\title{
Prevalence and predictors of Kaposi's sarcoma among HIV patients receiving care at a tertiary hospital in Jos, Nigeria
}

\author{
Jonathan C Daboer', Moses P Chingle', Fabian H Puepet ${ }^{2}$, Tyavyar J Akosu', Oche Agbaji ${ }^{3}$ \\ 1 Department of Community Medicine, College of Health Sciences, University of Jos, Nigeria, ${ }^{2}$ Department of Medicine, College of Health Sciences, \\ University of Jos, Nigeria, ${ }^{3}$ Department of Medicine, College of Health Sciences, University of Jos, Nigeria; APIN-Supported HIV Centre, Jos University \\ Teaching Hospital, Jos, Nigeria \\ Keywords: predictors, prevalence, haart, kaposi's sarcoma, hiv \\ https://doi.org/10.29392/001c.24349
}

Journal of Global Health Reports

Vol. 5, 2021

\begin{abstract}
Background
Kaposi's sarcoma became prevalent with the appearance of human immune deficiency virus (HIV) in the 1980s. However, the widespread use of the highly active antiretroviral therapy (HAART) reduced its prevalence in communities with good access to the antiretroviral drugs. The objective of this study was to determine the prevalence and predictors of Kaposi's sarcoma among persons receiving HIV care at a tertiary hospital in Jos, Nigeria.
\end{abstract}

\section{Methods}

The study used a cross-sectional study design, based on secondary data related to patients who had received HIV care between January 2004 and December 2017. Logistic regression was then used to determine the variables that were predictors of Kaposi's sarcoma risk.

\section{Results}

The prevalence of Kaposi's sarcoma among the patients was 1.2\% (95\% confidence interval, $\mathrm{CI}=1.06-1.34)$. Patients whose baseline viral loads were higher than 10,000 copies $/ \mathrm{mm}^{3}$ were three times more likely to develop Kaposi's sarcoma than those with lesser viral load (OR: 3.13, CI: 2.19-4.47). Gender, duration of HAART and education had modifying effect on the Kaposi's sarcoma risk.

\section{Conclusions}

Kaposi's sarcoma is a substantial public health problem among the HIV population in Jos. Universal access to HAART by the Federal Government of Nigeria and its partners is recommended to reduce its prevalence. In addition, education, skill acquisition and income generating programs should be targeted at girls and women by governments and other stakeholders in order to reduce the inequality that worsens their vulnerability to HIV infection and Kaposi's sarcoma.

Kaposi's sarcoma (KS) is an angio-proliferative malignancy that affects the endothelium of blood vessels. It predominantly affects the skin at different sites and can progress and regress depending on the immunity of the host. ${ }^{1} \mathrm{KS}$ is one of the most common malignancies in the world and the most important AIDS defining cancer (ADC). ${ }^{2}$ The Human Herpes Virus type 8 (HHV-8) is a necessary, but not sufficient cause of KS. ${ }^{3}$ The prevalence of KS is higher among the human immunodeficiency virus (HIV) infected population than the general population and it varies widely among different HIV infected populations. ${ }^{4-9}$

It is not certain what factors predict the development of KS among the HIV infected persons. In the late stages of the HIV infection, KS runs a very aggressive course, suggesting the modifying role of lowered immunity in its development and progression. ${ }^{9}$ However, some HIV patients treated with the highly active antiretroviral therapy (HAART), and who experience a substantial restoration of the CD4+ cell count have also been reported to develop KS, even at this stage, suggesting that there may be other factors at play. ${ }^{2}$ The advent of HAART has reduced the incidence of KS in Europe and North America, but disaggregated data even in such societies have provided evidence of stagnant or even worsening incidence of KS among certain population subgroups. ${ }^{9}$ This is often attributed to the inequality in access to HAART in those populations. In low- and middle-income countries (LMICs), access to HAART has been suboptimal, while the adherence to the prescribed regime is partial even in those patients who receive it. ${ }^{10}$ There appears to be a complex interplay of factors that interact among themselves to deter- 
mine the development of KS among those infected with the HIV. Besides the background HIV and HHV-8 infections, it is not known what other factors predict the development of KS among the HIV patients.

The objective of this study was to determine the prevalence of KS among HIV infected patients, who were receiving care at the tertiary hospital and the factors that predict the development of this malignancy among them.

\section{METHODS}

The study was conducted in the AIDS Prevention Initiative in Nigeria, APIN-supported HIV treatment and care centre of the Jos University Teaching Hospital in Jos, Nigeria. The Centre serves patients from all over central Nigeria. The Centre routinely collects the data from patients using standardized forms at three monthly interval visits. At first contact, all patients have their HIV infection status confirmed using double HIV rapid testing. They are then registered for care and the information recorded on each patient includes demographic characteristics and history of AIDS related conditions. Clinical investigations routinely done for the patients at baseline include full blood count, viral load, CD4+ count and chest X-rays. During follow up visits, CD4+ cell count and viral load estimation are repeated and recorded along with history of HAART over the follow up period. Any adverse events such as drug reactions, opportunistic infections, cancer development and any other illness are recorded. Diagnosis of Kaposi's sarcoma is based on the attending physician's diagnosis, supported by a histology report.

The study design was cross-sectional, based on the secondary data on adult HIV patients registered at the Centre between $1^{\text {st }}$ January 2004 and $31^{\text {st }}$ December 2017, irrespective of whether or not they received HAART. Inclusion criteria were adults aged 18 years and above and confirmed HIV infection status. Patients whose socio-demographic, HAART and HIV clinical/laboratory data were incomplete were excluded from the study.

The minimum sample size was estimated to be 139 using the formula for sample size estimation in cross sectional studies $\left(\mathrm{n}=\mathrm{Z}^{2} \mathrm{pq} / \mathrm{d}^{2}\right),{ }^{11}$ and the proportion of HIV patients who developed KS from a previous study (10\%). ${ }^{12}$ However, a total sample of all the records that met the inclusion criteria were included in the analysis. Data were imported into the IBM Statistical Package for Social Sciences (SPSS) version 21 for statistical analysis. Patients who developed KS were compared with those who did not develop the cancer using age groups, sex, baseline CD4+ cell count, end line CD4+ cell count, baseline viral load and end line viral load. Chi square test was used to test the association between socio-demographic factors and other clinical conditions on one hand and the development of KS on the other. Logistic regression was used to determine the factors that predict the development of KS in the patients using their odds ratios and 95\% confidence intervals. The independent variables in this model were the patients' age, sex, education, marital status, CD4+ cell count, and viral load while the dependent variable was the development of Kaposi's sarcoma.

Permission for the use of secondary data was obtained from the management of Treatment and Care Centre, APIN
Public Health Initiatives, and Harvard T. H. Chan School of Public Health, Boston, USA. In addition, the Centre had obtained an ethical approval from the institution's Health Research Ethics Committee for all research work involving data collected in the Centre which is renewed regularly. All data exported for analysis carried no personal identifying information on the individual patients and strict confidentiality was maintained.

\section{RESULTS}

The majority of the patients were aged between 31 and 50 years (70.3\%). A total of 16235 (65.4\%) of the patients were female and 15214 (63.0\%) had completed at least secondary school. Most of patients (54.9\%) were married at the time of registration for care (Table 1$)$.

There were 281 patients with the KS diagnosis among $24430 \mathrm{HIV}$ infected patients, yielding an overall KS prevalence of $1.2 \%$ (95\% C.I: 1.06 - 1.34; Table 2). Two hundred and fifty two (89.6\%) of the $281 \mathrm{KS}$ cases were aged between 30 and 59 years while 193 (67.5\%) of the 286 patients with KS were female, giving a male: female ratio of KS of $1: 2$. Most; 171 (61.1\%) of the KS cases were married.

Out of 22243 patients with baseline CD4+ counts of 500 cells/ml or less, 255 (1.2\%) developed KS, while 26 (1.3\%) of the 2071 patients with baseline CD4+ counts greater than 500 cells/ml developed KS (Table 3). At end of the study period, 187 (1.1\%) of the 16679 patients with CD4+ counts of 500 cells/ml or less developed KS and 90 (1.3\%) of the 7168 patients with CD4 count greater than 500 cell $/ \mathrm{ml}$ developed KS. There was no statistically significant relationship between level of CD4+ count and development of KS. Thirty five $(0.5 \%)$ of 6932 patients with baseline viral load of 1000 copies/ml or less developed KS whereas 230 (1.6\%) of the 14712 patients with baseline viral load greater than 1000 copies/ml developed KS. There was a statistically significant association between the baseline viral load and development of KS ( $\mathrm{p}<0.001)$. At the end of the study period, 152 (1.6\%) of the 9557 patients with viral load of 1000 copies/ $\mathrm{ml}$ or less developed KS while 93 (1.7\%) of 5484 with viral load greater than 1000 developed KS. There was no statistically significant association between end of study viral load and development of KS ( $\mathrm{p}=0.62)$.

Out of the 21149 patients who had received HAART for less than 10 years, 217 (1.1\%) developed KS compared to the 48 (3.5\%) of 1390 who had HAART for 10 or more years. There was a statistically significant association between duration on HAART and development of KS ( $\mathrm{P}<0.001$; Table 4). Eighty of the 24825 HIV infected patients also had tuberculosis infection giving a prevalence of $0.3 \%$ and 75 (93.7\%) out of the 80 patients with TB also developed KS. There was a statistically significant association between tuberculosis co-infection and development of KS ( $\mathrm{P}<0.001$; Table 5)

Gender, secondary school education, baseline viral load and duration on HAART were found to be independent predictors of KS). The odds ratios show that being male and attaining secondary level of education half the risk of development of KS while having been on HAART for ten years or more increases the risk of KS by $70 \%$ (Table 6). 
Table 1. Socio-demographic characteristics of patients in care in the Centre 2004-2017

\begin{tabular}{|c|c|c|}
\hline Characteristics & $\mathbf{N}$ & Percentage \\
\hline \multicolumn{3}{|c|}{ Age group (years) } \\
\hline$\leq 20$ & 93 & 0.4 \\
\hline $21-30$ & 1276 & 5.2 \\
\hline $31-40$ & 8250 & 33.8 \\
\hline $41-50$ & 8921 & 36.5 \\
\hline $51-60$ & 4381 & 17.9 \\
\hline$>60$ & 1507 & 6.2 \\
\hline Total & 24428 & 100.0 \\
\hline Mean age \pm SD & $43.8 \pm 9.2$ & \\
\hline \multicolumn{3}{|l|}{ Sex } \\
\hline Male & 8605 & 34.6 \\
\hline Female & 16235 & 65.4 \\
\hline Total & 24840 & 100.0 \\
\hline \multicolumn{3}{|l|}{ Marital status } \\
\hline Single & 5340 & 22.1 \\
\hline Married & 13260 & 54.9 \\
\hline Widowed & 3624 & 15.0 \\
\hline Divorced & 1936 & 8.0 \\
\hline Total & 24160 & 100.0 \\
\hline \multicolumn{3}{|c|}{ Highest education } \\
\hline No formal & 4125 & 17.0 \\
\hline Primary & 4825 & 20.0 \\
\hline Secondary & 7639 & 31.6 \\
\hline Tertiary & 7575 & 31.4 \\
\hline Total & 24164 & 100.0 \\
\hline
\end{tabular}

\section{DISCUSSION}

The prevalence of Kaposi's sarcoma among the HIV patients attending the treatment Centre was $1.2 \%$. The female gender, high baseline viral load and having been on HAART for 10 or more years were significant predictors of KS development, whereas having attained secondary level of education significantly reduced the risk of KS development.

The prevalence of KS in this study is lower than what was documented earlier in 2009 from the same Centre. ${ }^{13}$ The earlier study was conducted at a time when HAART just became available in Nigeria, therefore the true impact of HAART was largely unknown. In addition, the earlier study used a smaller sample size compared to the current study which could account for the difference in prevalence found in the two studies. The finding is similar to the $1.2 \%$ earlier found in Lagos, ${ }^{14}$ but lower than what was found in other studies. ${ }^{15,16}$ In Zaria, a city located in northern Nigeria, a KS prevalence of $1.4 \%$ was documented. ${ }^{17}$ All the findings above are, however, higher than the $0.6 \%^{8}$ and $0.8 \%^{4}$ found earlier in Kano and Abuja respectively.

As early as 1996, the prevalence of KS among HIV positive clients was said to be $0.52 \%$ in Lagos. ${ }^{18}$ It would appear that, although the prevalence of KS is still low among people living with HIV in Nigeria, it is showing an increasing trend. The figures obtained in this study are much lower than that from Sao Paulo, Brazil, where the prevalence of KS among persons on HAART was reported to be $6 \% .{ }^{5}$ In North America, the cumulative incidence of KS was recorded to be $4.4 \%$ in $2015 .{ }^{19}$ In LMICs, access to HAART is suboptimal and sero-prevalence of HHV-8 is reported to be as high as 20-30\%. ${ }^{1}$ These factors are likely to continue to drive the prevalence of KS in directions dictated by the balance of force between access to HAART and other protective factors against KS on one hand and HHV-8 and other KS risk factors on the other. Since the prevalence of KS is lower in Sub Saharan Africa (SSA) than in Europe and USA despite poorer access and adherence to HAART, other factors such as genetics, melanin content of the black skin and other environmental factors are probably protective against KS among the HIV infected population in SSA.

The male to female ratio of KS in this study was $1: 2$. This agrees with earlier findings of $1: 1.4^{13}$ and $1: 2^{20}$ in Jos but lower than that in Zaria. ${ }^{17}$ In Abuja and Kano, the M: F ratio was as high as $2: 1^{4}$ and $2.4: 1^{8}$ respectively. Before the advent of HIV, KS was about four times more common among the males than the females globally. ${ }^{1}$ However, the higher prevalence of HIV among women has tilted the balance to a higher prevalence of KS among the females than males in SSA. This position is supported by the data in this study 
Table 2. Socio-demographic characteristics of patients with KS and without KS in the Centre, 2004-2017.

\begin{tabular}{|c|c|c|c|c|c|}
\hline \multirow[t]{2}{*}{ Characteristics } & \multicolumn{5}{|c|}{ Presence of Kaposi's Sarcoma } \\
\hline & No (\%) & Yes (\%) & Total (\%) & $x^{2}$ & $\mathrm{P}$ \\
\hline \multicolumn{6}{|l|}{ Age group (years) } \\
\hline$<20$ & $93(0.4)$ & $0(0.0)$ & & $93(0.4)$ & \\
\hline $20-29$ & $1268(5.3)$ & $8(2.9)$ & $1276(5.2)$ & & \\
\hline $30-39$ & $8155(33.8)$ & $95(33.8)$ & $8250(33.8)$ & & \\
\hline $40-49$ & $8822(36.5)$ & $99(35.2)$ & $8921(36.5)$ & & \\
\hline $50-59$ & $4325(17.9)$ & $58(20.6)$ & $4383(17.9)$ & & \\
\hline$\geq 60$ & $1486(6.1)$ & $21(7.5)$ & $1507(6.2)$ & & \\
\hline Total & 24149(98.8) & $281(1.2)$ & $24430(100.0)$ & 6.223 & 0.285 \\
\hline \multicolumn{6}{|l|}{ Sex } \\
\hline Male & $8512(34.7)$ & $93(32.5)$ & $8605(34.6)$ & & \\
\hline Female & $16042(65.3)$ & $193(67.5)$ & $16235(65.4)$ & & \\
\hline Total & $24554(98.8)$ & $286(1.2)$ & $24840(100.0)$ & 0.577 & 0.448 \\
\hline \multicolumn{6}{|l|}{ Education } \\
\hline No Formal Education & $4079(17.1)$ & $46(16.4)$ & $4125(17.0)$ & & \\
\hline Primary & $4772(20.0)$ & $53(18.9)$ & $4825(24.1)$ & & \\
\hline Secondary & 7552 (31.6) & $87(31.1)$ & 7639 (31.6) & & \\
\hline Tertiary & $7481(31.3)$ & $94(33.6)$ & 7575 (31.3) & & \\
\hline Total & $23884(98.8)$ & $280(1.2)$ & $24164(100.0)$ & 0.695 & 0.874 \\
\hline \multicolumn{6}{|l|}{ Marital Status } \\
\hline Single & $5281(22.1)$ & $57(20.3)$ & $5338(22.1)$ & & \\
\hline Married & $13091(54.8)$ & $171(61.1)$ & $13262(54.9)$ & & \\
\hline Widowed & $3593(15.1)$ & $31(11.1)$ & $3624(15.0)$ & & \\
\hline Divorced/separated & $1915(8.0)$ & $21(7.5)$ & $1936(8.0)$ & & \\
\hline Total & $23880(98.8)$ & $280(1.2)$ & $24160(100.0)$ & 4.690 & 0.196 \\
\hline
\end{tabular}

where majority of the HIV infected persons in care were women.

Majority of those who developed KS in this study were young. This compares well with what was obtained in Abuja. ${ }^{4}$ A similar study in Lagos found the modal age group for HIV patients with KS to be 40-49 years. In the era of HIV, KS tends to occur at a younger age and this is even more so for the female gender. ${ }^{4}$ This pattern is distinct from the classical KS which occurs typically in the elderly. It is possible that other factors acting indirectly may also play a role in influencing KS outcome since, elsewhere, age had no effect on the risk of development of KS. ${ }^{21}$

The prevalence of KS appears to increase with increasing level of education. Although it was not statistically significant in this study, other studies found elevated prevalence of KS among those who have attained higher education, in occupations that are well paid and who travel widely. ${ }^{22}$ It is believed that this increased prevalence is related to increased risk of exposure to sexually transmitted agents. Unexpectedly, KS was more commonly found among men married to one wife than men married to multiple spouses in that study. ${ }^{22}$ It is possible that the men's marital status masked their actual sexual practices as many men in monogamous marriages have many other sexual partners outside marriage. In this study almost two thirds of the KS patients were currently married but this could be due to the fact that more than half of the study population were currently married. There was however no statistically significant relationship between marital status and development of KS.

In this study, CD4+ cell counts did not affect the KS outcome even though the median CD4+ cell counts both at baseline and at the end of the study period were higher for those without KS compared to those with KS. Patients who had baseline viral load greater than 1000 copies $/ \mathrm{ml}$ were three times more likely to develop KS than those with baseline viral load of 1000 copies/ml or less. The median baseline viral load was also higher among those with KS compared with those without KS. These finding are in agreement with those from a number of studies which have linked the immunologic and virologic status of patients to their risk of development of KS. ${ }^{15,16}$ In an earlier study in Jos Nigeria, the median CD4+ cell count was significantly higher among those who did not have KS compared with those who had. However against expectation, the median viral load was higher among those without KS compared to those with KS in that study. ${ }^{21}$ It has been reported that as part of the immune reconstitution syndrome, some patients with low viral load and high CD4+ cell count could develop $\mathrm{KS}^{2}$ In Lagos Nigeria, HAART and high CD4+ cell count 
Table 3. Kaposi's sarcoma and HIV characteristics of patients in care in the Centre 2004-2017

HIV Characteristics

\begin{tabular}{|c|c|c|c|c|}
\hline \multicolumn{5}{|c|}{ Kaposi's sarcoma } \\
\hline & No (\%) & Yes (\%) & Total & $P$ \\
\hline \multicolumn{5}{|c|}{ CD4 cells/ml } \\
\hline \multicolumn{5}{|c|}{ Baseline } \\
\hline$\leq 500$ & $21988(98.8)$ & $255(1.2)$ & 22243 & \\
\hline$>500$ & 2045 (98.7) & $26(1.3)$ & 2071 & 0.683 \\
\hline Total & $24033(98.8)$ & $281(1.2)$ & 24314 & \\
\hline Median & $171(79-308)$ & $98(50-200)$ & & \\
\hline \multicolumn{5}{|c|}{ End of study } \\
\hline$\leq 500$ & $16492(98.9)$ & $187(1.1)$ & 16679 & \\
\hline$>500$ & 7078 (98.7) & $90(1.3)$ & 7168 & 0.371 \\
\hline Total & $23570(98.8)$ & $277(1.2)$ & 23847 & \\
\hline Median & $351(168-545)$ & $217(95-468)$ & & \\
\hline \multicolumn{5}{|c|}{ Viral load copies/ml } \\
\hline \multicolumn{5}{|l|}{ Baseline } \\
\hline$\leq 1000$ & $6897(99.5)$ & $35(0.5)$ & 6932 & \\
\hline$>1000$ & $14482(98.4)$ & $230(1.6)$ & 14712 & $<0.001$ \\
\hline Total & $21379(98.8)$ & $265(1.2)$ & 21644 & \\
\hline Median & $35977(4736-155877)$ & 55825 (8493-176775) & & \\
\hline \multicolumn{5}{|c|}{ End of study } \\
\hline$\leq 1000$ & 9405 (98.4) & $152(1.6)$ & 9557 & \\
\hline$>1000$ & $5391(98.3)$ & $93(1.7)$ & 5484 & 0.624 \\
\hline Total & $14796(98.4)$ & $245(1.6)$ & 15041 & \\
\hline Median & $200(0-9878)$ & $200(0-24809)$ & & \\
\hline
\end{tabular}

Table 4. Duration on HAART and development of Kaposi sarcoma among patients in care in the Centre 2004-2017

\begin{tabular}{|c|c|c|c|}
\hline \multicolumn{4}{|c|}{ Kaposi's sarcoma } \\
\hline Duration on HAART (years) & Yes (\%) & No (\%) & Total \\
\hline$<10$ & $217(1.1)$ & 20932 (98.9) & $21149(100.0)$ \\
\hline$\geq 10$ & $48(3.5)$ & $1342(96.5)$ & $1390(100.0)$ \\
\hline Total & 265 (1.2) & 22274 (98.8) & $22539(100.0)$ \\
\hline
\end{tabular}

$\mathrm{X}^{2}=66.13, \mathrm{df}=1, \mathrm{P}<0.001$

were found to selectively reduce the risk of malignancy especially KS and Non-Hodgkin's Lymphoma (NHL). ${ }^{14}$ Also in Kenya, those HIV infected persons with CD4+ cell counts less than 350 cells/ml had 7 times increased risk of KS compared to those with higher CD4+ cell counts. ${ }^{23}$ In the USA and South America the risk of KS was found to be inversely related to the CD4+ cell count. ${ }^{5,24}$ In another study, low CD4+ cell count, not being on HAART and non-cancer AIDS diagnosis like tuberculosis were predictors of ADCs. ${ }^{25}$

The use of HAART as such did not influence the KS outcome in this study contrary to the finding elsewhere in which the use of HAART was protective against KS. ${ }^{26}$ However, patients who had been on HAART for less than ten years were less likely to develop KS than those who had received HAART for ten years or more. The duration on HAART was probably a proxy indicator of the duration of HIV infection. In those reported to be on HAART for longer periods, the long duration of immunosuppression associated with poor adherence to HAART probably increased their risk of development of KS. This is more so that the optimum benefits of HAART are only obtained with adherence of at least $80 \%,{ }^{27,28}$ and patients with imperfect adherence to HAART are 20 times more likely to develop KS than those with perfect adherence. ${ }^{23}$ Unfortunately, it is not known at what point in their illness the patients developed KS; before or after the commencement of HAART. Therefore, the rela- 
Table 5. Relationship between Tuberculosis Infection and Kaposi's sarcoma among patients in care in the Centre, 2004-2017

\begin{tabular}{|c|c|c|c|}
\hline \multicolumn{4}{|c|}{ Kaposi Sarcoma } \\
\hline Tuberculosis & Absent (\%) & Present (\%) & Total (\%) \\
\hline Absent & 24549(99.2) & 196(0.8) & $24745(100.0)$ \\
\hline Present & $5(6.3)$ & 75(93.7) & $80(100.0)$ \\
\hline Total & $24554(98.9)$ & 271(1.1) & $24825(100.0)$ \\
\hline
\end{tabular}

$X^{2}=6381.87, \mathrm{df}=1, \mathrm{p}<0.001$

Table 6. Predictors of Kaposi's sarcoma among HIV infected persons attending clinic in the Centre, 2004-2017

\begin{tabular}{|c|c|c|c|}
\hline Parameter & $\mathrm{p}$ & Odds Ratio (OR) & $95 \%{ }^{*}$ C.I of OR \\
\hline \multicolumn{4}{|l|}{ Age } \\
\hline \multicolumn{4}{|l|}{$21-30$} \\
\hline $30-39$ & 0.876 & 1.10 & $0.32-3.78$ \\
\hline $40-49$ & 0.847 & 0.92 & $0.38-2.24$ \\
\hline $50-59$ & 0.712 & 0.85 & $0.36-2.01$ \\
\hline$\geq 50$ & 0.408 & 1.44 & $0.61-3.42$ \\
\hline \multicolumn{4}{|l|}{ Gender } \\
\hline Female & & 1 & \\
\hline Male & 0.024 & 0.56 & $0.33-0.93$ \\
\hline \multicolumn{4}{|l|}{ Education } \\
\hline No formal education & & 1 & \\
\hline Primary & 0.368 & 0.75 & $0.39-1.41$ \\
\hline Secondary & 0.026 & 0.47 & $0.24-0.91$ \\
\hline Tertiary & 0.372 & 0.78 & $0.46-1.34$ \\
\hline \multicolumn{4}{|l|}{ Alcohol use } \\
\hline No & & 1 & \\
\hline Yes & 0.107 & 0.68 & $0.42-1.09$ \\
\hline \multicolumn{4}{|l|}{ HBSAg } \\
\hline Negative & & 1 & \\
\hline Positive & 0.561 & 0.87 & $0.55-1.38$ \\
\hline \multicolumn{4}{|l|}{ HCV antibody } \\
\hline Negative & & 1 & \\
\hline Positive & 0.631 & 0.88 & $0.51-1.51$ \\
\hline \multicolumn{4}{|c|}{ Baseline viral load (copies/ml) } \\
\hline$\leq 1000$ & & 1 & \\
\hline$>1000$ & 0.004 & 3.13 & $2.19-4.47$ \\
\hline \multicolumn{4}{|l|}{ On HAART } \\
\hline No & & 1 & \\
\hline Yes & 0.841 & 1.05 & $0.65-1.69$ \\
\hline \multicolumn{4}{|l|}{ Duration on HAART } \\
\hline$\geq 10$ years & 0.000 & 1 & $0.19-0.50$ \\
\hline$<10$ years & & 0.31 & \\
\hline
\end{tabular}

*C.I: Confidence interval

tionship between duration on HAART and development of fection.

KS should be interpreted in terms of the duration of HIV in- In a logistic regression model, this factor was found to 
be a strong predictor of KS development as those who had been on HAART for ten years or more had their risk of development of KS increased by $70 \%$. Prolonged exposure to HIV and poor adherence to HAART allow prolonged immunosuppression with increased risk of KS. ${ }^{29-31}$ The public health and policy implication of this finding is that the current 'test and treat' policy of government is not sufficient until strict adherence is ensured among HIV infected patients on HAART. This will also minimize the potential for drug resistance and treatment failure.

One of the biggest problems in this study was the missing data. A possible way forward in this situation would be a cohort multicenter study, which could allow for the determination of incidence per person years of follow up.

\section{CONCLUSIONS}

This study found a low prevalence of Kaposi's sarcoma among HIV infected adults receiving care at the Treatment and Care Centre in Jos, Nigeria. Patients on HAART for more than ten years had up to $70 \%$ higher risk of development of KS than those on HAART for less than ten years. Other factors found to be predictors of KS development in these patients included the female gender, low education and high baseline viral load. Measures to improve adherence to HAART among HIV patients as well as female education and empowerment are recommended.

\section{ACKNOWLEDGEMENTS}

This publication is supported by the NIH/FIC funded grant, titled Support of Training and Mentoring in Nigeria for Academics (D43TW010130). Also, this work was funded, in part, by the U.S. Department of Health and Human Services,
Health Resources and Services Administration (U51HA02522) and the Centers for Disease Control and Prevention (CDC) through a cooperative agreement with APIN (PS 001058). The contents are solely the responsibility of the authors and do not represent the official views of the funding institutions.

\section{FUNDING}

As above.

\section{AUTHORSHIP CONTRIBUTIONS}

Concept and study design - DJC, CMP and PFH. Data collection - DJC. Data analysis and interpretation - DJC, CMP and PFH. Drafting of article - DJC. Revising the article critically for important intellectual content - AO and ATJ. All the authors revised and approved the final version of the article for publication. DJC takes overall responsibility for questions and integrity of the work.

\section{COMPETING INTERESTS}

The authors completed the Unified Competing Interest form at www.icmje.org/coi_disclosure.pdf (available upon request from the corresponding author) and declare no conflicts of interest.

\section{CORRESPONDENCE TO:}

Dr Jonathan C. Daboer, MBBS, MSc, FMCPH (Nigeria) Department of Community Medicine, Faculty of Clinical Sciences, College of Health Sciences, University of Jos P.M.B 2084 Jos, Plateau State, Nigeria jonathandabor@yahoo.co.uk

Submitted: April 28, 2021 GMT, Accepted: May 13, 2021 GMT 


\section{REFERENCES}

1. La Ferla L, Lo Presti CM, Mondello P. Kaposi's sarcoma in HIV-infected patients: A Review of the Literature. Infect Dis Trop Med. 2016;2(1):E239.

2. Cobucci RNO, Lima PH, De Souza PC, et al. Assessing the impact of HAART on the incidence of defining and non-defining AIDS cancers among patients with HIV/AIDS: A systematic review. Journal of Infection and Public Health. 2015;8(1):1-10. doi:10.1 016/i.jiph.2014.08.003

3. Campbell TB, Borok M, White IE, et al. Relationship of Kaposi's Sarcoma Associated Viremia and Kaposi's Sarcoma Disease in Zimbabwe. Clinical Infectious Diseases. 2003;36(9):1144-1151. $\underline{\text { doi:10.108 }}$ $\underline{6 / 374599}$

4. Iregbu KC, Elegba OY. Prevalence of Kaposi's sarcoma among adult HIV seropositive patients seen in a designated treatment and care center in Abuja, Nigeria. J Int Assoc Physicians AIDS care. 2006;5(3):115-118. doi:10.1177/1545109706290176

5. Tancredi MV, Pinto VM, da Silva MH, et al. Prevalence of kaposi's sarcoma in patients with AIDS and associated factors, Sao Paulo-SP Brazil 2003-2010. Epidemiol Serv Saude. 2017;26(2):379-387. doi:10.5123/s1679-49742017000200015

6. Rohner E, Valeri F, Maskew M, et al. Incidence rate of kaposi's sarcoma in HIV-infected patients on Antiretroviral therapy in southern Africa: a prospective multi-cohort study. J Acquir Immune defic Syndr. 2014;67(5):547-554. doi:10.1097/qai.00000000 $\underline{00000360}$

7. Akarolo-Anthony SN, Maso LD, Igbinoba F, Mbulaiteye SM, Adebamowo CA. Cancer burden among HIV-positive persons in Nigeria: Preliminary findings from the Nigerian AIDS-cancer match study. Infect Agent Cancer. 2014;9(1):1. doi:10.1186/1750-93 78-9-1

8. Gwaram BA, Yusuf SM. Clinical presentation and treatment outcome of HIV associated kaposi's sarcoma in a tertiary health centre in Nigeria. The Journal of Medical Research. 2016;2(4):110-113.

9. Royse KE, El Chaer F, Amirian ES, et al. Disparities in Kaposi sarcoma incidence and survival in the United States: 2000-2013. Cai Q, ed. PLoS ONE. 2017;12(8):e0182750. doi:10.1371/journal.pone.0182 $\underline{750}$
10. Oku AO, Owoaje ET, Oku OO, Monjok E. Prevalence and Determinants of Aherence to Highly Active AntiRetroviral Therapy Amongst People Living With HIV/AIDS in a Rural Community in South-South Nigeria. Afr J Reprod Health. 2014;18(1):133-144.

11. Ogbonna C. Sample size determination. In: The Basics in Biostatistics, Medical Informatics and Research Methodology. Yakson Printing Press; 2014:225-229.

12. Chen $\mathrm{CH}$, Chung CY, Wang LH, Lin C, Lin HL, Lin HC. Risk of cancer among HIV-infected patients from a population-based nested case-control study: Implications for cancer prevention. BMC Cancer. 2014;15(1):133. doi:10.1186/s12885-015-1099-y

13. Agaba PA, Sule HM, Ojoh RO, et al. Presentation and survival of patients with AIDS-related Kaposi's sarcoma in Jos, Nigeria. Int J STD AIDS. 2009;20(6):410-413. doi:10.1258/ijsa.2008.008353

14. Akinde O, Obadofin O, Adeyemo T, et al. Kaposi Sarcoma among HIV infected Patients in Lagos University Teaching Hospital, Nigeria: A 14 year Retrospective Clinicopathological Study. J Skin Cancer. 2016;2016:1-6. doi:10.1155/2016/9368023

15. Semango GP, Charles RM, Swai CI, et al. Prevalence and associated risk factors for Kaposi's sarcoma among HIV-positive patients in a referral hospital in Northern Tanzania: A retrospective hospital-based study. BMC Cancer. 2018;18(1):1258. $\underline{\mathrm{d}}$ oi:10.1186/s12885-018-5155-2

16. Nansseu JR, Kouotou EA, Tounouga DN, Bissek ACZK. Determinants of Kaposi Sarcoma during HIV infection: A nested case-control study from Yaoundé, Cameroon. Infection, Disease \& Health.

2018;23(4):217-224. doi:10.1016/j.idh.2018.07.003

17. Ahmed A, Muktar HM, Bugaje MA. pidemiology and clinical features of AIDS-associated kaposi's sarcoma in northern Nigeria. Arch Int Surg. 2013;3(1):29-34. doi:10.4103/2278-9596.117132

18. Akinsete I, Akanmu AS, Okany CC. Spectrum of clinical disease in HIV-infected adults at the Lagos University Teaching Hospital: A five-year experience [1992-1996]. Afr J Med Med Sci. 1998;27:147-151.

19. Silverberg MJ, Lau B, Achenbach CJ, et al. Cumulative Incidence of Cancer among Persons with HIV in North America: A cohort study. Ann Intern Med. 2015;163(7):507-524. doi:10.7326/m14-2768 
20. Ngbea JA, Dzuachii OD, Agada E, et al. Histopathological pattern of HIV/AIDS-Related kaposi's sarcoma in Jos North Central Nigeria. IOS Journal of Dental and Medical Sciences. 2015;14(4):101-104.

21. Lodi S, Guiguet M, Costagliola D, et al. Kaposi's sarcoma Incidence and Survival Among HIV-infected Homosexual men after seroconversion. J Natl Cancer Inst. 2010;102(11):784-792. doi:10.1093/inci/diq134

22. Ziegler JL, Newton R, Katongole-Mbidde E, et al. Risk factors for Kaposi's sarcoma in HIV-positive subjects in Uganda. AIDS. 1997;11(13):1619-1626. do i:10.1097/00002030-199713000-00011

23. Lupia R, Wabuyia PB, Otiato P, Fang CT, Tsai FJ. Risk factors for Kaposi's sarcoma in human immunodeficiency virus patients after initiation of antiretroviral therapy: A nested case-control study in Kenya. Journal of Microbiology, Immunology and Infection. 2017;50(6):781-788. doi:10.1016/j.jmii.201 $\underline{5.10 .009}$

24. Engels EA, Biggar RJ, Hall HI, et al. Cancer risk in people infected with human immunodeficiency virus in the United States. Int J Cancer. 2008;123(1):25-36. doi:10.1002/ijc.23487

25. Crum-Cianflone N, Hullsiek KH, Satter E, et al. Cutaneous malignancies among HIV infected persons. Arch Intern Med. 2009;169(12):1130-1138. do i:10.1001/archinternmed.2009.104
26. Liu Z, Fang Q, Zuo J, Minhas V, Wood C, Zhang T. The world-wide incidence of kaposi's sarcoma in the HIV/AIDS era. HIV Med. 2018;19(5):355-364. doi:10.1 111/hiv.12584

27. Martinez V, Caumes E, Gambotti L, et al. Remission from Kaposi's sarcoma on HAART is associated with suppression of HIV replication and is independent of protease inhibitor therapy. $\mathrm{Br} J$ Cancer. 2006;94(7):1000-1006. doi:10.1038/sj.bjc.660 $\underline{3056}$

28. Lynen L, Zolfo M, Huyst V, et al. Management of Kaposi's sarcoma in Resource-limited Settings in the Era of HAART. AIDS Reviews. 2005;7:13-21.

29. Nguyen HQ, Magaret AS, Kitahata MM, Van Rompaey SE, Wald A, Casper C. Persistent Kaposi's sarcoma in the era of HAART: characterizing the predictors of clinical response. AIDS. 2008;22(8):937-945. doi:10.1097/qad.0b013e3282ff62 $\underline{75}$

30. Viswanathan S, Detels R, Mehta SH, Macatangay BJC, Kirk GD, Jacobson LP. Level of adherence and HIV RNA suppression in the current era of full Highly Active Antiretroviral Therapy (HAART). AIDS Behav. 2015;19(4):601-611. doi:10.1007/s10461-014-0927-4

31. Bezabhe WM, Chalmers L, Bereznicki LR, Peterson GM. Adherence to Antiretroviral Therapy and virologic failure: a meta-analysis. Medicine. 2016;95(15):1-9. 